Annals of Pure and Applied Mathematics

Vol. 14, No. 2, 2017, 255-262

ISSN: 2279-087X (P), 2279-0888(online)

Published on 7 September 2017

www.researchmathsci.org

DOI: http://dx.doi.org/10.22457/apam.v14n2a8

Annals of

Pure and Applied Mathematics

\title{
A Common Fixed Point Theorem Using Compatible Mappings of Type (A-1)
}

\section{V.Nagaraju ${ }^{1}$ and Bathini Raju ${ }^{2}$}

${ }^{1}$ Department of Mathematics, University College of Engineering (Autonomous) Osmania University, Hyderabad-500007 (Telangana), India

${ }^{2}$ Department of Mathematics, University Post Graduate College, Secunderabad Osmania University, Hyderabad-500003 (Telangana), India

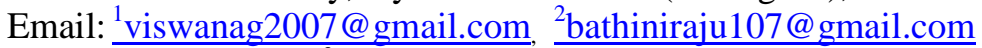

\author{
${ }^{2}$ Corresponding author
}

Received 19 July 2017; accepted 31 August 2017

Abstract. In this paper we present a common fixed point theorem in a metric space using the weaker conditions such as compatible mappings of type (A-1) and associated sequence which generalizes the result of P.C.Lohani \& V.H.Badshah.

Keywords: Fixed point, self maps, compatible mappings of type (A-1), associated sequence.

AMS Mathematics Subject Classification (2010): 54H25, 47H10

\section{Introduction}

In 1976, Jungck proved some common fixed point theorems for commuting maps which generalize the Banach contraction principle. Further these results were generalized and extended in various ways by several authors. On the other hand Sessa [5] introduced the concept of weak commutativity and proved a common fixed point theorem for weakly commuting maps. In 1986, Jungck [1] introduced the concept of compatible maps which is more general than that of weakly commuting maps. In 1993, Jungck and Cho [7] introduced the concept of compatible mappings of type (A) by generalizing the weakly uniformly contraction maps. Afterwards Pathak and Khan [10] introduced the concepts of A-compatibility and S-compatibility by splitting the definition of compatible mappings of type (A). In 2007, Pathak et.al [8] renamed Acompatibility and S-compatibility as compatible mappings of type (A-1) and compatible mappings of type (A-2) respectively.

The purpose of this paper is to prove a common fixed point theorem for four self maps in a metric space using compatible mappings of type (A-1). 


\section{V.Nagaraju and Bathini Raju}

\section{Definitions and preliminaries}

Definition 2.1. [1] Two self maps $S$ and $T$ of a metric space $(X, d)$ are said to be compatible mappings if $\lim _{n \rightarrow \infty} d\left(S T x_{n}, T S x_{n}\right)=0$ whenever $\left\langle x_{n}\right\rangle$ is a sequence in $\mathrm{X}$ such that $\lim _{n \rightarrow \infty} S x_{n}=\lim _{n \rightarrow \infty} T x_{n}=t$ for some $t \in X$.

Definition 2.2. [7] Two self maps $S$ and $T$ of a metric space $(X, d)$ are said to be compatible mappings of type (A) if $\lim _{n \rightarrow \infty} d\left(S T x_{n}, T T x_{n}\right)=0$ and $\lim _{n \rightarrow \infty} d\left(T S x_{n}, S S x_{n}\right)=0$ whenever $\left\langle x_{n}\right\rangle$ is a sequence in $\mathrm{X}$ such that $\lim _{n \rightarrow \infty} S x_{n}=\lim _{n \rightarrow \infty} T x_{n}=t$, for some $t \in X$.

Definition 2.3. [8] Two self maps $S$ and $T$ of a metric space $(X, d)$ are said to be compatible mappings of type(A-1) if $\lim _{n \rightarrow \infty} d\left(T S x_{n}, S S x_{n}\right)=0$ whenever $\left\{x_{n}\right\}$ is a sequence in X such that $\lim _{n \rightarrow \infty} S x_{n}=\lim _{n \rightarrow \infty} T x_{n}=t$, for some $t \in X$.

Definition 2.4. [9] Suppose $\mathrm{P}, \mathrm{Q}, \mathrm{S}$ and $\mathrm{T}$ are self maps of a metric space $(X, d)$ such that $S(X) \subset Q(X)$ and $T(X) \subset P(X)$. Then for any arbitrary $x_{0} \in X$, we have $S x_{0} \in S(X) \subset Q(X)$ so that there is a $x_{1} \in X$ such that $S x_{0}=Q x_{1}$ and for this $x_{1}$, there is a point $x_{2} \in \mathrm{X}$ such that $T x_{1}=P x_{2}$ and so on. Repeating this process to obtain a sequence $<x_{n}>$ in $\mathrm{X}$ such that $y_{2 n}=S x_{2 n}=Q x_{2 n+1}$ and $y_{2 n+1}=P x_{2 n+2}=T x_{2 n+1}$ for $n \geq 0$. We shall call this sequence $\left\langle x_{n}>\right.$ an "associated sequence of $x_{0}$ relative to the four self maps $\mathrm{P}, \mathrm{Q}, \mathrm{S}$ and $\mathrm{T}$.

Lemma 2.5. Let $\mathrm{P}, \mathrm{Q}, \mathrm{S}$ and $\mathrm{T}$ be self mappings from a metric space $(X, d)$ into itself satisfying

$$
S(X) \subset Q(X) \text { and } T(X) \subset P(X)
$$

and $d(S x, T y) \leq \alpha \frac{d(Q y, T y)[1+d(P x, S x)]}{[1+d(P x, Q y)]}+\beta d(P x, Q y)$

for all $x, y$ in $X$ where $\alpha, \beta \geq 0, \alpha+\beta<1$.

Further if $\mathrm{X}$ is complete, then for any $\mathrm{x}_{0} \in \mathrm{X}$ and for any of its associated sequence $\left\{\mathrm{X}_{n}\right\}$ relative to four self maps, the sequence 
A Common Fixed Point Theorem Using Compatible Mappings of Type (A-1)

$\left\{y_{n}\right\}=\left\{S x_{0}, T x_{1}, S x_{2}, T x_{3}, \ldots . . S x_{2 n}, T x_{2 n+1}, \ldots ..\right\}$ converges to some point in X.

Proof: From (2.4) and (2.5.2), we have

$$
\begin{aligned}
d\left(y_{2 n}, y_{2 n+1}\right) & =d\left(S x_{2 n}, T x_{2 n+1}\right) \\
& \leq \alpha \frac{d\left(Q x_{2 n+1}, T x_{2 n+1}\right)\left[1+d\left(P x_{2 n}, S x_{2 n}\right)\right]}{\left[1+d\left(P x_{2 n}, Q y_{2 n+1}\right)\right]}+\beta d\left(P x_{2 n}, Q y_{2 n+1}\right) \\
& =\alpha \frac{d\left(y_{2 n}, y_{2 n+1}\right)\left[1+d\left(y_{2 n-1}, y_{2 n}\right)\right]}{\left[1+d\left(y_{2 n-1}, y_{2 n}\right)\right]}+\beta d\left(y_{2 n-1}, y_{2 n}\right) \\
& =\alpha d\left(y_{2 n,} y_{2 n+1}\right)+\beta d\left(y_{2 n-1}, y_{2 n}\right) \text { implies that }
\end{aligned}
$$

$(1-\alpha) d\left(y_{2 n}, y_{2 n+1}\right) \leq \beta d\left(y_{2 n-1}, y_{2 n}\right)$ so that

$d\left(y_{2 n}, y_{2 n+1}\right) \leq \frac{\beta}{(1-\alpha)} d\left(y_{2 n-1}, y_{2 n}\right)=h d\left(y_{2 n-1}, y_{2 n}\right)$, where $h=\frac{\beta}{1-\alpha}$.

That is, $d\left(y_{2 n}, y_{2 n+1}\right) \leq h\left(y_{2 n-1}, y_{2 n}\right)$.

Similarly, we can prove that $d\left(y_{2 n+1}, y_{2 n+2}\right) \leq h d\left(y_{2 n}, y_{2 n+1}\right)$.

Hence, from (2.5.3) and (2.5.4), we get

$$
d\left(y_{n}, y_{n+1}\right) \leq h d\left(y_{n-1}, y_{n}\right) \leq h^{2} d\left(y_{n-2}, y_{n-1}\right) \leq \ldots \ldots . \leq h^{n} d\left(y_{0}, y_{1}\right) .
$$

Now for any positive integer $\mathrm{p}$, we have

$$
\begin{aligned}
d\left(y_{n}, y_{n+p}\right) & \leq d\left(y_{n}, y_{n+1}\right)+d\left(y_{n+1}, y_{n+2}\right)+\ldots \ldots . .+d\left(y_{n+p-1}, y_{n+p}\right) \\
& \leq h^{n} d\left(y_{0}, y_{1}\right)+h^{n+1} d\left(y_{0}, y_{1}\right)+\ldots \ldots . .+h^{n+p-1} d\left(y_{0}, y_{1}\right) \\
& =\left(h^{n}+h^{n+1}+\ldots \ldots . .+h^{n+p-1}\right) d\left(y_{0}, y_{1}\right) \\
& =h^{n}\left(1+h+h^{2}+\ldots \ldots .+h^{p-1}\right) d\left(y_{0}, y_{1}\right) \\
< & \frac{h^{n}}{1-h} d\left(y_{0}, y_{1}\right) \rightarrow 0 \text { as } \mathrm{n} \rightarrow \infty, \text { since } \mathrm{h}<1 .
\end{aligned}
$$

Thus the sequence $\left\{y_{n}\right\}$ is a Cauchy sequence in $\mathrm{X}$. Since $\mathrm{X}$ is a complete metric space, the sequence $\left\{y_{n}\right\}$ converges to some point $\mathrm{z}$ in $\mathrm{X}$. 


\section{V.Nagaraju and Bathini Raju}

Remark 2.6. The converse of the above Lemma is not true. That is, if $P, Q, S$ and $T$ are self maps of a metric space $(X, d)$ satisfying $(2.5 .1),(2.5 .2)$ and even if for any $x_{0}$ in $X$ and for any of its associated sequence converges, then the metric space $(X, d)$ need not be complete.

Example 2.7. Let $X=(0,2]$ with $d(x, y)=|x-y|$ for $x, y \in X$. Define the self maps $\mathrm{S}, \mathrm{T}, \mathrm{P}$ and $\mathrm{Q}$ on $\mathrm{X}$ by

$$
S x=T x=\left\{\begin{array}{l}
1-x \text { if } 0<x \leq \frac{1}{2} \\
\frac{1}{2} \quad \text { if } \frac{1}{2}<x \leq 1
\end{array} \text { and } P x=Q x=\left\{\begin{array}{l}
2-3 x \text { if } 0<x \leq \frac{1}{2} \\
3 x-1 \text { if } \frac{1}{2}<x \leq 1
\end{array}\right.\right.
$$

Then $S(X)=T(X)=\left[\frac{1}{2}, 1\right)$ while $P(X)=Q(X)=\left[\frac{1}{2}, 2\right]$.

Clearly $S(X) \subset Q(X)$ and $T(X) \subset P(X)$. It is also easy to see that the sequence $S x_{0}, T x_{1}, S x_{2}, T x_{3}, \ldots . . S x_{2 n}, T x_{2 n+1}, \ldots . .$. converges to $\frac{1}{2}$. Also the inequality (2.5.2) can easily be verified for appropriate values of $\alpha, \beta \geq 0, \alpha+\beta<1$. Note that $(\mathrm{X}, \mathrm{d})$ is not complete.

Now we generalize the result of P.C.Lohani and V.H.Badshah [6] in the following form.

\section{Main result}

We now state our main theorem as follows.

Theorem 3.1. Let $\mathrm{P}, \mathrm{Q}, \mathrm{S}$ and $\mathrm{T}$ are self maps of a metric space $(X, d)$ satisfying

$$
\begin{aligned}
& S(X) \subset Q(X) \text { and } T(X) \subset P(X) \\
& d(S x, T y) \leq \alpha \frac{d(Q y, T y)[1+d(P x, S x)]}{[1+d(P x, Q y)]}+\beta d(P x, Q y)
\end{aligned}
$$

for all $\mathrm{x}, \mathrm{y}$ in $\mathrm{X}$ where $\alpha, \beta \geq 0, \alpha+\beta<1$.

$\mathrm{P}$ and $\mathrm{Q}$ are continuous and the pairs (S,P) and (T,Q) are compatible mappings of type (A-1) on X . (3.1.4) Further if there is point $x_{0} \in X$ and an associated sequence $\left\{x_{n}\right\}$ of $\mathrm{x}_{0}$ relative to four self maps $\mathrm{P}, \mathrm{Q}, \mathrm{S}$ and $\mathrm{T}$ such that the sequence

$$
S x_{0}, T x_{1}, S x_{2}, T x_{3} \ldots . . . S x_{2 n}, T x_{2 n+1} \ldots \text { converges to some point } z \in X \text {, }
$$


A Common Fixed Point Theorem Using Compatible Mappings of Type (A-1) then $\mathrm{z}$ is a unique common fixed point of $\mathrm{S}, \mathrm{P}, \mathrm{Q}$ and $\mathrm{T}$.

Proof: By (3.1.5), we have

$S x_{2 n} \rightarrow z, Q x_{2 n+1} \rightarrow z, T x_{2 n+1} \rightarrow z$ and $P x_{2 n+2} \rightarrow z$ as $n \rightarrow \infty$

Suppose the pair (S,P) is compatible mappings of type(A-1).

Then we have $\lim _{n \rightarrow \infty} P S x_{2 n}=\lim _{n \rightarrow \infty} S S x_{2 n}$

Since $\mathrm{P}$ is continuous, $P P x_{2 n}, P S x_{2 n} \rightarrow P z$ as $n \rightarrow \infty$

Now from (3.1.7) and (3.1.8), we get $S S x_{2 n} \rightarrow P z$ as $n \rightarrow \infty$.

Suppose the pair $(\mathrm{T}, \mathrm{Q})$ is compatible mappings of type(A-1).

Then we have $\lim _{n \rightarrow \infty} Q T x_{2 n+1}=\lim _{n \rightarrow \infty} T T x_{2 n+1}$.

Since $\mathrm{Q}$ is continuous, $Q Q x_{2 n}, Q T x_{2 n+1} \rightarrow Q z$ as $n \rightarrow \infty$.

Now from (3.1.10) and (3.1.11), we get $\operatorname{TTx}_{2 n+1} \rightarrow Q z$ as $n \rightarrow \infty$.

We shall now prove that $P z=Q z=S z=T z=z$.

To prove $P z=Q z$, put $x=S x_{2 n}$ and $y=T x_{2 n+1}$ in (3.1.2), we get

$d\left(S S x_{2 n}, T T x_{2 n+1}\right) \leq \alpha \frac{d\left(Q T x_{2 n+1}, T T x_{2 n+1}\right)\left[1+d\left(P S x_{2 n}, S S x_{2 n}\right)\right]}{\left[1+d\left(P S x_{2 n}, Q T x_{2 n+1}\right)\right]}+\beta d\left(P S x_{2 n}, Q T x_{2 n+1}\right)$. Letting $n \rightarrow \infty$ and using (3.1.8), (3.1.9), (3.1.10), (3.1.11) and (3.1.12) in the above inequality, we get

$$
\begin{aligned}
d(P z, Q z) & \leq \alpha \frac{d(Q z, Q z)[1+d(P z, P z)]}{[1+d(P z, Q z)]}+\beta d(P z, Q z) \\
& =\beta d(P z, Q z) \text { so that }
\end{aligned}
$$

$(1-\beta) d(P z, Q z) \leq 0$.

Since $\beta \geq 0, \alpha+\beta<1$, we have $d(P z, Q z)=0$ which implies $P z=Q z$.

To prove $S z=Q z$, put $x=z$ and $y=T x_{2 n+1}$ in (3.1.2), we get $d\left(S z, \operatorname{TTx}_{2 n+1}\right) \leq \alpha \frac{d\left(Q T x_{2 n+1}, T T x_{2 n+1}\right)[1+d(P z, S z)]}{\left[1+d\left(P z, Q T x_{2 n+1}\right)\right]}+\beta d\left(P z, Q T x_{2 n+1}\right)$.

Letting $n \rightarrow \infty$ and using (3.1.11) and (3.1.12) in the above inequality, we get $d(S z, Q z) \leq \alpha \frac{d(Q z, Q z)[1+d(P z, S z)]}{[1+d(P z, Q z)]}+\beta d(P z, Q z)$

which implies

$d(S z, Q z) \leq 0$, since $P z=Q z$.

Hence $d(S z, Q z)=0$ which implies $S z=Q z$. 
Therefore $P z=S z=Q z$.

To prove $S z=T z$, put $x=z$ and $y=z$ in (3.1.2), we get

$$
\begin{aligned}
d(S z, T z) & \leq \alpha \frac{d(Q z, T z)[1+d(P z, S z)]}{[1+d(P z, Q z)]}+\beta d(P z, Q z) \\
= & \alpha \frac{d(S z, T z)[1+d(S z, S z)]}{[1+d(P z, P z)]}+\beta d(P z, P z), \text { since } P z=Q z=S z .
\end{aligned}
$$

$d(S z, T z) \leq \alpha d(S z, T z)$ so that

$(1-\alpha) d(S z, T z) \leq 0$.

Since $\alpha \geq 0, \alpha+\beta<1$, we have $d(S z, T z)=0$ which implies $S z=T z$.

Therefore $S z=P z=Q z=T z$.

Finally to prove $T z=z$, put $x=x_{2 n}$ and $y=z$ in (3.1.2), we get

$d\left(S x_{2 n}, T z\right) \leq \alpha \frac{d(Q z, T z)\left[1+d\left(P x_{2 n}, S x_{2 n}\right)\right]}{\left[1+d\left(P x_{2 n}, Q x_{2 n}\right)\right]}+\beta d\left(P x_{2 n}, Q z\right)$

Letting $n \rightarrow \infty$ and using (3.1.6) in the above inequality, we get

$$
\begin{gathered}
d(z, T z) \leq \alpha \frac{d(T z, T z)[1+d(z, z)]}{[1+d(z, z)]}+\beta d(z, T z) \\
=\beta d(z, T z) \text { so that } \\
(1-\beta) d(z, T z) \leq 0 .
\end{gathered}
$$

Since $\alpha \geq 0, \alpha+\beta<1$, we have $d(z, T z)=0$ which implies $T z=z$.

Therefore $S z=P z=Q z=T z=z$, showing that $z$ is a common fixed point of $\mathrm{P}, \mathrm{Q}, \mathrm{S}$ and T.

Uniqueness: Let $\mathrm{z}$ and $\mathrm{w}$ be two common fixed points of $\mathrm{P}, \mathrm{Q}, \mathrm{S}$ and $\mathrm{T}$. Then we have $z=S z=P z=Q z=T z$ and $w=S w=P w=Q w=T w$.

Put $\mathrm{x}=\mathrm{z}$ and $\mathrm{y}=\mathrm{w}$ in (3.1.2), we get

$$
\begin{aligned}
d(z, w) & \leq \alpha \frac{d(w, w)[1+d(z, z)]}{[1+d(z, w)]}+\beta d(z, w) \\
& =\beta d(z, w) \\
& <\mathrm{d}(\mathrm{z}, \mathrm{w}), \text { a contradiction. }
\end{aligned}
$$

Thus we have $d(z, w)=0$ which implies that $z=w$.

Hence $\mathrm{z}$ is a unique common fixed point of $\mathrm{S}, \mathrm{P}, \mathrm{Q}$ and $\mathrm{T}$. 
A Common Fixed Point Theorem Using Compatible Mappings of Type (A-1)

Remark 3.2. From the example (2.7), clearly the pairs (S,P) and (Q,T) are compatible mappings of type(A-1) and $\mathrm{P}, \mathrm{Q}$ are continuous. Also, if we take $x_{n}=\frac{1}{2}+\frac{1}{n}$ for $n \geq 1$, then the sequence $S x_{0}, T x_{1}, S x_{2}, T x_{3} \ldots . . S x_{2 n}, T x_{2 n+1} \ldots$ converges to $\frac{1}{2} \in X$.Moreover, the rational inequality holds for the values of $\alpha, \beta \geq 0, \alpha+\beta<1$.It may be noted that ' $\frac{1}{2}$, is the unique common fixed point of $\mathrm{P}, \mathrm{Q}, \mathrm{S}$ and $\mathrm{T}$.

\section{REFERENCES}

1. G.Jungck, Compatible mappings and common fixed points, Internat. J. Math. Math. Sci., 9 (1986) 771-778.

2. R.P.Pant, A Common fixed point theorem under a new condition, Indian J. of Pure and App. Math., 30(2) (1999) 147-152.

3. Jungck, Compatible mappings and common fixed points (2), Internat. J. Math. And Math. Sci., 11(1988) 285-288.

4. G.Jungck and B.E. Rhoades, Fixed point for set valued functions without continuity, Indian J. Pure Appl. Math, 29(3) (1998), 227-238.

5. S.Sessa, On a weak commutativity condition in a fixed point considerations, Publ. Inst Math. (Beograd), 32(46)(1982) 149-153.

6. P.C.Lohani and V.H.Badshah, Compatible mappings and common fixed point for four mappings, Bull. Cal. Math. Soc., 90(1998) 301-308.

7. G.Jungck, P.P.Murthy and Y.J.Cho, Compatible mappings of type (A) and common fixed points, Math. Japan, 38 (1993) 381-391.

8. M.S.Khan, H.K.Pathak and George Reny, Compatible mappings of type (A-1) and type(A-2) and common fixed points in fuzzy metric spaces, International Math. Forum, 2(11)(2007) 515-524.

9. V.Srinivas and V.Nagaraju, Common fixed point theorem on compatible mappings of type (P), Gen. Math. Notes, 21(2) (2014) 87-94.

10. H.K.Pathak and M.S.Khan, A comparison of various types of compatible maps and common fixed points, Indian J. Pure Appl. Math, 28(4) (1997) 477-485.

11. V.Srinivas and S.Ravi, Generation of a common fixed point theorem using Acompatible and B-compatible mappings of type(E), Global Journal of Pure and Applied Mathematics, 13(6) (2017) 1735-1744.

12. K.Jha, R.P.Pant and K.B.Manadhar, A common fixed point theorem for reciprocally continuous compatible mappings in metric space, Annals of Pure and Applied Mathematics, 5(2) (2014) 120-124. 


\section{V.Nagaraju and Bathini Raju}

13. K.Jha, M.Imdad and U.Upadhyaya, Fixed Point theorems for occasionally weakly compatible mappings in metric space, Annals of Pure and Applied Mathematics, 5(2) (2014) 153-157.

14. P.Malviya, V.Gupta and V.H.Badshah, Common fixed point theorem for semi compatible pairs of reciprocal continuous maps in menger spaces, Annals of Pure and Applied Mathematics, 11(2) (2016)139-144. 